\title{
SARS-CoV-2 associated Miller-Fisher syndrome or polyneuritis cranialis
}

\author{
Josef Finsterer ${ }^{1}$ (D) \\ Received: 17 March 2021 / Accepted: 4 June 2021 / Published online: 11 June 2021 \\ (C) The Author(s), under exclusive licence to Springer-Verlag GmbH Germany, part of Springer Nature 2021
}

Keywords SARS-CoV-2 $\cdot$ COVID-19 $\cdot$ Polyneuritis cranialis $\cdot$ Miller-Fisher syndrome $\cdot$ Ophthalmoparesis

Letter to the Editor: With interest, we read the review article by Li et al. about 7 patients with SARS-CoV-2-associated Miller-Fisher syndrome (MFS) (Li et al. 2021). It was found that the most common clinical manifestations of SARS-CoV-2 associated MFS are perioral paresthesias $(57.1 \%)$, ataxia $(57.1 \%)$, blurred vision (42.9), ophthalmoplegia (42.9), and generalized areflexia ( $\mathrm{Li}$ et al. 2021). The report is interesting but raises the following comments and concerns.

As per the end of March 2021 at least 13 patients with SARS-CoVassociated MFS or polyneuritis cranialis (PNC) have been reported (Dinkin et al. 2020, Garnero et al. 2020, Gutiérrez-Ortiz et al. 2020, Juliao Caamaño and Alonso 2020, Kajani et al. 2021, Lantos et al. 2020, Lowery et al. 2020, Manganotti et al. 2020, Ray 2020, ReyesBueno et al. 2020, Senel et al. 2020). In a recent review about SARSCoV-2 associated Guillain Barre syndrome (GBS) collected until the end of December 2020, 11 patients with MFS or PNC were identified (Finsterer et al. 2021). Of these 11 patients, 2 patients had MFS plus PNC and one patient MFS plus acute, inflammatory demyelinating polyneuropathy (AIDP) (Finsterer et al. 2021). In addition to these 11 cases, SARS-CoV-2-associated MFS was reported by Kajani et al. (2021) and Manganotti et al. (2020).

Age of these 13 patients ranged from 32 to 71 years (Table 1). Ten patients were male and 3 female (Table 1). Onset was identified after/before onset of non-neurological COVID-19 manifestations in 12/1 patients (Table 1). Latency between onset of COVID-19 and MFS/PNC ranged from 1 to 20 days. SARS-CoV-2 was not detected in the CSF in any of the patients (Table 1). Therapy of MFS comprised intravenous immunoglobulins (IVIG) in 9 patients, steroids in 1 patient, and three patients did not receive any therapy (Table 1 ).

Responsible Editor: Philippe Garrigues

Josef Finsterer

fifigs1@yahoo.de

1 Klinik Landstrasse, Messerli Institute, Postfach 20, Vienna, Austria
Full recovery was achieved in 6 patients, partial recovery in 6 patients, and one patient died (Table 1). This review showed that the outcome of SARS-CoV-2-associated MFS/PNC is fair and that not only cranial nerves III, IV, and VI supplying the extra-ocular eye muscles can be affected in MFS but also other cranial nerves and also the peripheral nerves.

Concerning the methods of the study, it is unclear why PubMed was searched for appropriate hits only at a single day and not repeatedly. Searching the database only once can be associated with overlooking appropriate articles. Furthermore, application of only "MFS" as a search term is insufficient given the fact that MSF may be overlapping with other subtypes of GBS. Additional helpful search terms could be "ophthalmoparesis", "polyneuritis cranialis", "ptosis", or "oculomotor nerve palsy".

It is mentioned that COVID-19 was diagnosed in five of the seven patients prior to onset of MFS, suggesting that the diagnosis of COVID19 in the two remaining patients was established after onset of MFS. If MFS developed before COVID-19 in two patients, it is conceivable that MFS in these two patients was not causally related to COVID-19 but may have another etiology. The statement that the temporal relationship between MFS and COVID-19 was not reported in three patients does not comply with the information that COVID-19 was diagnosed before/after onset of MFS in $5 / 2$ patients.

A further shortcoming is that anti-GQ1b antibodies were detected in only a single patient. The fact that not all MFS patients were tested positive GQ1b is interesting as GQ1b antibodies are reported positive in up to $100 \%$ of the cases (Teener 2012). A further limitation is that the 7 cases included in the review were not referenced. 
Table 1 SARS-CoV-2-associated MFS reported as per the end of March 2021

\begin{tabular}{|c|c|c|c|c|c|c|c|c|c|c|c|}
\hline Age (y) & Sex & Onset & LOO (d) & Subtype & CIC & Comorbitities & IVIG & $\mathrm{AV}$ & Recovery & Country & Reference \\
\hline 50 & M & A & 3 & MFS, PNC & No & No & Yes & No & Yes & Spain & Gutiérrez-Ortiz et al. (2020) \\
\hline 39 & M & $\mathrm{A}$ & 3 & MFS, PNC & No & No & No & No & Yes & Spain & Gutiérrez-Ortiz et al. (2020) \\
\hline 61 & M & $\mathrm{A}$ & 10 & MFS & No & No & S & No & Yes & Spain & Juliao Caamaño and Alonso (2020) \\
\hline 36 & M & A & 4 & MFS & $\mathrm{nr}$ & $\mathrm{nr}$ & Yes & No & Yes & USA & (Lantos et al. 2020) \\
\hline 51 & $\mathrm{~F}$ & $\mathrm{~A}$ & 14 & MFS & $\mathrm{nr}$ & $\mathrm{nr}$ & Yes & No & Partial & Spain & (Reyes-Bueno et al. 2020) \\
\hline 34 & M & A & 4 & $\mathrm{PNC}$ & $\mathrm{nr}$ & Strabism & Yes & No & Partial & USA & (Dinkin et al. 2020) \\
\hline 71 & $\mathrm{~F}$ & A & Days & $\mathrm{PNC}$ & $\mathrm{nr}$ & AHT & No & No & Partial & USA & (Dinkin et al. 2020) \\
\hline 49 & M & A & 14 & MFS & No & Crohn's disease & Yes & Yes & Partial & USA & (Lowery et al. 2020) \\
\hline 55 & M & $\mathrm{A}$ & 20 & AIDP/MFS & No & $\mathrm{nr}$ & Yes & No & Partial & Italy & (Garnero et al. 2020) \\
\hline 63 & M & $\mathrm{A}$ & 1 & MFS & $\mathrm{nr}$ & $\mathrm{nr}$ & No & No & Partial & UK & (Ray 2020) \\
\hline 61 & M & A & $\mathrm{nr}$ & MFS & No & $\mathrm{nr}$ & Yes & No & Yes & Germany & (Senel et al. 2020) \\
\hline 50 & M & $\mathrm{B}$ & Days & MFS & No & DM, heroin, obesity & Yes & Yes & Death & USA & (Kajani et al. 2021) \\
\hline 50 & $\mathrm{~F}$ & A & 16 & MFS & $\mathrm{nr}$ & No & Yes & No & Yes & Italy & (Manganotti et al. 2020) \\
\hline
\end{tabular}

$A$ onset of GBS after onset of non-neurological manifestations, $A H T$ arterial hypertension, $A V$ artificial ventilation, $B$ onset of GBS before onset of nonneurological manifestations, $C I C$ CoV2 in CSF, $D M$ diabetes, $F$ female, $L O O$ latency between onset of GBS and COVID-19, respectively, vice versa, $M$ male, $n r$ not reported, $P N C$ polyneuritis cranialis, $S$ steroids

Overall, the review is appealing but has several limitations which should be accomplished before drawing conclusions as those presented.

Author contribution JF: design, literature search, discussion, first draft, critical comments

Data availability Not applicable

\section{Declarations}

Ethics approval The study was approved by the institutional review board.

Consent to participate Not applicable

Consent for publication Not applicable

Informed consent Informed consent was obtained.

Conflict of interest The author declares no competing interest.

\section{References}

Dinkin M, Gao V, Kahan J, Bobker S, Simonetto M, Wechsler P, Harpe J, Greer C, Mints G, Salama G, Tsiouris AJ, Leifer D (2020) COVID19 presenting with ophthalmoparesis from cranial nerve palsy. Neurology. 95(5):221-223. https://doi.org/10.1212/WNL. 0000000000009700

Finsterer J, Scorza FA. Guillain-Barre syndrome in 220 patients with COVID-19. Egypt J Neurol Psychiatr Neurosurg. 2021;57(1):55. https://doi.org/10.1186/s41983-021-00310-7
Garnero M, Del Sette M, Assini A, Beronio A, Capello E, Cabona C, Reni L, Serrati C, Bandini F, Granata A, Pesce G, Mancardi GL, Uccelli A, Schenone A, Benedetti L (2020) COVID-19-related and not related Guillain-Barré syndromes share the same management pitfalls during lock down: the experience of Liguria region in Italy. $\mathrm{J}$ Neurol Sci 418:117114. https://doi.org/10.1016/j.jns.2020.117114

Gutiérrez-Ortiz C, Méndez A, Rodrigo-Rey S, San Pedro-Murillo E, Bermejo-Guerrero L, Gordo-Mañas R, de Aragón-Gómez F, Benito-León J (2020) Miller Fisher syndrome and polyneuritis cranialis in COVID-19. Neurology. https://doi.org/10.1212/WNL. 0000000000009619.

Juliao Caamaño DS, Alonso BR (2020) Facial diplegia, a possible atypical variant of Guillain-Barré syndrome as a rare neurological complication of SARS-CoV-2. J Clin Neurosci 77:230-232. https://doi. org/10.1016/j.jocn.2020.05.016

Kajani S, Kajani R, Huang CW, Tran T, Liu AK (2021) Miller Fisher syndrome in the COVID-19 era - a novel target antigen calls for novel treatment. Cureus. 13(1):e12424. https://doi.org/10.7759/ cureus. 12424

Lantos JE, Strauss SB, Lin E (2020) COVID-19-Associated Miller Fisher syndrome: MRI findings. AJNR Am J Neuroradiol 41(7):1184 1186. https://doi.org/10.3174/ajnr.A6609

Li Z, Li X, Shen J, Chan MTV, Wu WKK (2021) Miller Fisher syndrome associated with COVID-19: an up-to-date systematic review. Environ Sci Pollut Res Int 6:1-6. https://doi.org/10.1007/s11356021-13233-w

Lowery MM, Taimur Malik M, Seemiller J, Tsai CS (2020) Atypical variant of Guillain Barre syndrome in a Patient with COVID-19. J Crit Care Med (Targu Mures) 6(4):231-236. https://doi.org/10. 2478/jccm-2020-0038

Manganotti P, Pesavento V, Buoite Stella A, Bonzi L, Campagnolo E, Bellavita G, Fabris B, Luzzati R (2020) Miller Fisher syndrome diagnosis and treatment in a patient with SARS-CoV-2. J Neuro-Oncol 26(4):605-606. https://doi.org/10.1007/s13365020-00858-9 
Ray A (2020) Miller Fisher syndrome and COVID-19: is there a link? BMJ Case Rep 13(8):e236419. https://doi.org/10.1136/bcr-2020236419

Reyes-Bueno JA, García-Trujillo L, Urbaneja P, Ciano-Petersen NL, Postigo-Pozo MJ, Martínez-Tomás C, Serrano-Castro PJ (2020) Miller-Fisher syndrome after SARS-CoV-2 infection. Eur J Neurol 27(9):1759-1761. https://doi.org/10.1111/ene.14383

Senel M, Abu-Rumeileh S, Michel D, Garibashvili T, Althaus K, Kassubek J, Otto M (2020) Miller-Fisher syndrome after COVID-
19: neurochemical markers as an early sign of nervous system involvement. Eur J Neurol 27(11):2378-2380. https://doi.org/10. 1111/ene. 14473

Teener JW (2012) Miller Fisher's syndrome. Semin Neurol 32(5):512516. https://doi.org/10.1055/s-0033-1334470

Publisher's note Springer Nature remains neutral with regard to jurisdictional claims in published maps and institutional affiliations. 